\title{
HUMILLACIÓN, LA EXCLUSIÓN DE LA HUMANIDAD
}

Humiliation, the exclusion from humanity

\author{
LUIS MUÑOZOLIVEIRA \\ Universidad Nacional autónoma de México \\ munozoliveira@gmail.com
}

Resumen

En la discusión filosófica acerca de la justicia, Amartya Sen, pero también, por ejemplo, Garzón Valdés y el mismo Villoro, sostienen que resulta más urgente alejarnos de la injusticia que concentrarnos en "lo justo". En este contexto, aquí sostengo que la humillación de la dignidad es precisamente un criterio al que debemos voltear a ver cuando hablamos de lo inaceptable, que es donde se inicia la vía negativa hacia la justicia. Para ello, exploro los argumentos de Luis Villoro, Amartya Sen y Martha Nussbaum. Más adelante clarifico el vínculo entre la humillación y la exclusión, para sugerir que en ciertos contextos, y en específico el de la injusticia, el uso del concepto humillación resulta más útil que el de exclusión.

Palabras clave: Humillación; Exclusión; Villoro; Nussbaum; Sen.

Abstract:

Among those who discuss about the concept of Justice, Amartya Sen, but also Garzón Valdés and Villoro, claim that it is more urgent to walk away from injustice, than to concentrate our efforts in finding the meaning of Justice. Here I argue that the humiliation of dignity is a good yardstick to use when we talk about the unacceptable, where the negative way towards Justice begins. For that purpose I explore the arguments of Villoro, Sen, and Nussbaum. Finally, I make clear the link between humiliation and exclusion to suggest that in some contexts, and specifically in that of injustice, the use of the concept of humiliation can result more useful than that of exclusion.

Key words: Humiliation; Exclusion; Villoro; Nussbaum; Sen.

\section{INTRODUCCIÓN}

En este texto intentaremos mostrar que el uso del concepto de "humillación de la dignidad" puede resultar, en ciertos contextos, más útil que usar el de "exclusión". Además, es el concepto idóneo para comenzar a transitar la vía negativa hacia la justicia que defienden, entre otros, Luis Villoro y Amartya Sen ${ }^{1}$

\footnotetext{
${ }^{1}$ Todo esto abona a la idea de justicia de Avishai Margalit, quien defiende que una "sociedad decente" es aquella que no humilla por medio de sus instituciones. Suma también al uso del concepto de "humillación" en las discusiones acerca de justicia, desigualdad y dignidad.
} 
Nuestra hoja de ruta será la siguiente, primero exploraremos los argumentos de Luis Villoro, Amartya Sen y Martha Nussbaum, para mostrar desde ahí que la humillación de la dignidad es inaceptable. Más tarde defenderemos el vínculo entre la humillación y la exclusión. A nuestro parecer el vínculo es muy claro: la exclusión es negar la equidad y pertenencia a la sociedad de consenso a los distintos, donde "equidad" es trato igual ante la aplicación de una regla o norma. Quien no puede gozar de las libertades básicas estipuladas en la constitución de su sociedad, es tratado con inequidad y está excluido al menos respecto de esta norma fundamental. Tal carencia en el ejercicio de las libertades también es ausencia de capacidades. Para Nussbaum, como veremos, vivir bajo cierto umbral de capacidades es indigno de un ser humano y además es injusto. Dicho todo esto, si la humillación de la dignidad es la violación ilícita de la dignidad humana, entonces la falta de capacidades y la exclusión son humillación de la dignidad. Por último, como dijimos, intentaremos mostrar muy brevemente que el concepto de "humillación de la dignidad" parece más útil en ciertos contextos que el de exclusión o el de desigualdad, para señalar lo que Villoro llama el mal radical, ese punto del que debemos alejarnos, el inicio de la vía negativa hacia la justicia.

\section{LA VÍA NEGATIVA A LA JUSTICIA}

Sin duda, dice Luis Villoro (2007), el dolor físico y el del ánimo son cosa de todos los días, pero el dolor que nos causa el otro de manera injustificada es particular: ese daño sin justificación es el mal radical; experimentarlo es padecer la injusticia. La historia humana está llena de intentos de escapar de tal daño y, por supuesto, como dice Villoro, esto implica un impulso para escapar del mundo donde reina la injusticia, que, a diferencia de lo que sostiene Trasímaco ${ }^{2}$, es indeseable. Esa es la vía negativa.

El camino que propone Villoro se compone de tres momentos, que, bien nos aclara, no son etapas sucesivas sino estados de complejidad en el desarrollo de un orden moral. Pasemos a mencionarlos y explicarlos brevemente, para luego centrarnos en la exclusión.

1) La experiencia de la exclusión es la etapa donde la carencia causada por un daño se hace consciente. Para Villoro, "daño" es padecer un sufrimiento causado por un agente, personalizado o no ("la sociedad" puede ser agente de daño). Pero "daño" también es la exclusión forzada de bienes específicos que satisfacen ciertas necesidades. Por supuesto, a cada carencia le corresponderá una conciencia de exclusión distinta: "la carencia del obrero no es la misma que la del indio o la mujer y, por lo tanto, su conciencia de falta no puede

\footnotetext{
${ }^{2}$ Villoro se refiere al primer libro de La República de Platón, donde Trasímaco le dice a Sócrates que cuando la injusticia es cometida en una escala suficientemente amplia como para quedar impune, como sucede con los tiranos, que secuestran no solo la propiedad, sino también a los ciudadanos, entonces en vez de decírseles nombres oprobiosos, se dice de ellos que están benditos y son felices por haber cometido una injusticia completa. Una injusticia, de esta magnitud, dice, es más libre, más poderosa y más genial, que la justicia (ver Platón, 344 b).

52 | AlPHA No50 (Julio 2020) PÁGS. 51-65. ISSN 07 16-4254
} 
ser la misma" (Villoro, 2007, p. 21). Así, la diversidad de exclusiones y de experiencias de exclusión nos conducen forzosamente a reivindicaciones heterogéneas, cada una derivada de la propia experiencia de exclusión: no hay un único mal que combatir.

2) La equiparación con el excluyente es el momento en el que quienes experimentan el daño de la exclusión pasan de decir "por la carencia que tengo soy diferente a ti" a reconocer que "y sin embargo soy igual que tú". Entonces comienza la batalla, que puede ser violenta o expresarse en un duelo de palabras. "Por diferentes que sean sus fuerzas, poder y contrapoder se miden en el campo de la sociedad" (p. 24). Romper el consenso es el primer paso para "escapar del poder". Este disenso razonado abre dos vías: o bien caminamos hacia la controversia, o bien a la resistencia. Este segundo paso de la vía negativa, dice él, puede llevarnos a la ruptura o al deterioro de toda comunicación; pero también puede llevarnos a un reconocimiento del otro, un estado de cosas menos injusto.

3) El tercer momento es el reconocimiento del otro hacia una ética concreta, donde el excluido fundamenta racionalmente su reivindicación. Esto puede conducir a promulgar normas universalizables. Para llegar aquí, tomamos la ruta negativa que implica mostrar normas y valores que no excluyan más a nadie para, de esta forma, remediar exclusiones, daños, humillaciones concretas. Así, el criterio de universalización que se utiliza en la vía negativa es el siguiente: serán univerzalisables las normas y principios que no excluyan a ninguna persona.

Para Villoro, cuando se utiliza la vía negativa, se hace desde una Ética concreta que no tiene como fin el deseo ocioso del bien común en abstracto, sino la voluntad de que se realice a partir de acciones particulares. Según nos dice, desde esta postura, una acción se justifica cuando conduce a que los valores morales objetivos se realicen. El impulso para dejar la injusticia requiere dos tipos de conocimiento: saber cuáles son los valores objetivos que constituyen el bien común y cuáles las situaciones que llevarán a que tales valores se realicen (Villoro, 2012, p.123). Es importante señalar brevemente que "valor" se puede usar como "lo deseado", como aquello frente a lo que las personas tienen una actitud positiva. Y también como "lo deseable", es decir, aquello frente a lo que todo aquel que se encuentre en ciertas circunstancias, verá como verdaderamente benéfico para cualquiera. La atribución subjetiva de valor refleja un hecho: "x es deseable para y". En cambio, la atribución objetiva de valor es la conclusión de un razonamiento del que se sigue que cualquiera que conociera tal objeto o escuchara las razones de su valía, tendría que tener una actitud positiva frente a este. 


\section{LA CONCIENCIA DE LA EXCLUSIÓN}

Cuando Villoro señala que el camino que ha de andarse en su vía negativa es concreto y situado ${ }^{3}$, está haciendo una descripción, pero también enuncia el resultado de una crítica: para él la búsqueda de la justicia no se puede hacer a partir de un ser humano idealizado, completamente racional y libre, situado tras un velo de ignorancia, como pretendía Rawls y en algún sentido parecido (pero sin velo) Habermas: "las críticas de algunos autores calificados de comunitaristas no carecen de razón; solo personas concretas, situadas en un contexto social, regidas por razones pero también por pasiones, pueden realizar convenios, porque solo ellas son agentes morales, capaces de elegir con libertad" (Villoro, 2000, p. 108) ${ }^{4}$. Así, para comenzar a andar la vía negativa, tenemos que partir de personas situadas, pertenecientes a una cultura.

Desde que la persona nace está inmersa en un contexto que le hereda usos y costumbres, creencias, intenciones y preferencias consensuadas que se encuentran expresadas en reglas, ya sean tácitas o proclamadas y que la mayoría acepta, lo que a la postre resulta en un eficaz pegamento que mantiene unidas las diversidades. En esta moralidad se socializa el individuo y es a partir de ella que desarrolla una primera dimensión moral. Así, nos dice Villoro, "las reglas de la moralidad social constituyen sistemas normativos que regulan los comportamientos de la mayoría de los miembros de la sociedad. Podemos interpretar el consenso fáctico como un pacto tácito de convivencia entre la mayoría de los sujetos sociales. El concepto de la justicia vigente es resultado de ese acuerdo tácito" (p. 109).

La idea de justicia que organiza una sociedad traza dos tipos de límites, nos dice Villoro. Por un lado separa a quienes están de acuerdo con la idea de bien común, de quienes están excluidos de dicho consenso. Además, divide las diferencias que merecen un trato equitativo de las diferencias que son inaceptables. Los sujetos del consenso social aceptan como "normales" los valores comunes. Debido a esto, no se detienen a pensarlos y actúan comúnmente a partir de ellos. Entre estos sujetos existen diferencias: de clase, de educación, de raza, de creencias, de inclinaciones sexuales, por decir algunas. La idea de justicia en la que hay consenso establece qué diferencias pueden ser aceptadas y cuáles son inadmisibles. Debido a su diferencia, "la comunidad de consenso no puede tomar en

\footnotetext{
${ }^{3}$ En este texto no podemos explayarnos acerca de este asunto, pero vale la pena señalarlo: la discusión concerniente a humillación de la dignidad nos parece de suma relevancia para el contexto latinoamericano, debido a las características específicas de la región: una larga historia de humillación acompañada de riqueza (mal distribuida). Esto último es muy importante porque significa que tenemos a la mano los recursos para remediar muchas de las indignidades que padece la población latinoamericana, en contraste, por ejemplo, con las zonas más pobres del continente africano.

${ }^{4}$ Aquí no es posible que entremos a la polémica entre el sujeto moral que propone el liberalismo y las críticas que le hace el comunitarismo, pues tal debate no afecta los asuntos que tratamos. Traemos a colación la cita de Villoro para mostrar su desacuerdo con la aproximación que hacen a la Justicia autores como Rawls.

54 | AlPHA No50 (Julio 2020) PÁGS. 51-65. ISSN 07 16-4254
} 
cuenta sus preferencias; al no considerarlos sujetos iguales; tampoco puede admitirlos como interlocutores del pacto político, salvo en los aspectos que no toquen a esa diferencia" (p. 112) .

La exclusión se da a partir de una diferencia del excluido. Debido a esta diferencia se le excluye de una relación o un bien social. Por ejemplo, las mujeres no podían votar porque se consideraba (falsamente, por supuesto) que no tenían la sagacidad necesaria para saber de lo público. Además, como se las excluía de la educación superior, también se argumentaba que no tenían conocimientos en el asunto. El movimiento sufragista se "equiparó con el excluyente", dio ese duelo argumental, y ayudó a cambiar el statu quo.

El consenso alrededor de una idea de justicia genera un conjunto imaginario que no incluye a otra comunidad posible que incluiría a quienes tienen la nota diferencial. Se experimenta una exclusión cuando se comprueba la falta de coincidencia entre la comunidad de consenso conformada por sujetos "normales" y esa otra comunidad posible. "Al experimentar la exclusión comprobamos que la moralidad consensuada no realiza valores objetivos, puesto que descarta las preferencias de los excluidos" (p. 112). Es preciso señalar, como indica Villoro, que el paso de la experiencia personal de la exclusión a constatar que estamos ante una injusticia no es inmediato, requiere de una reflexión respecto del rechazo:

Justicia es un valor común. Luego, solo podemos concluir a una injusticia si a alguien se le rechaza el acceso a ese valor común. Debemos demostrar, por tanto, que el excluido tiene el mismo derecho que el excluyente a un trato justo [...] Por ello, debe demostrar que el excluido es un sujeto con los mismos derechos que los que lo excluyen y que su aceptación forma parte de un valor común (p. 113).

Ese valor común, cuando hablamos de humillación, es la igual dignidad. Para Villoro, la Justicia establece una igualdad de trato, es la igualdad en la aplicación de una regla y él prefiere llamar a este tipo de igualdad "equidad", para así distinguirla de la igualdad de propiedades (1 es igual a 1). Está última igualdad resulta en homogeneidad, la primera admite lo distinto. La exclusión es negar equidad y pertenencia a la sociedad de consenso a los distintos.

En las sociedades contemporáneas la desigualdad puede generar una diferencia que a su vez genera exclusión. Por ejemplo, las desigualdades en alimentación, salud, educación, dice Villoro, son resultado de la marginación del sistema social y esto a su vez provoca diferencias que excluyen a los pobres del resto: "tratar a los desiguales como personas rechazables por diferentes es prolongar las exclusiones que les dieron origen. Por

\footnotetext{
${ }^{5}$ Es conveniente apuntar que al decir "salvo en aspectos que no toquen a esa diferencia" Villoro deja claro que entiende que la distinción inclusión/exclusión entendida de manera binaria es poco útil. Las personas nunca están ni totalmente excluidas ni totalmente incluidas (Mascareño y Carvajal, 2015, p. 144).
} 
ello la justicia implica [...] la rectificación de las exclusiones históricas anteriores que dieron lugar a desigualdades" (Villoro, 2000, p. 118).

Entre las exclusiones patentes en nuestras sociedades, Villoro señala una: la exclusión de las libertades básicas que permiten dar sentido a la vida propia a partir de elegir lo que es valioso para cada quien. En las constituciones latinoamericanas, por hablar de las sociedades que le preocupan a Villoro y a nosotros también, esa libertad está protegida por el orden jurídico, pero en muchos países de la región no existen las condiciones para que todos los ciudadanos gocen de dichas libertades básicas. Villoro defiende que para poder ser libre y realizar lo que elige, un individuo debe tener satisfechas ciertas necesidades de sobrevivencia y de convivencia (alimentación, habitación, vestido, seguridad, pertenencia a una sociedad). Y es que, según afirma, "nadie es libre si carece de un tercer género de libertad: la de realización de lo que elige" (p. 121). En este sentido, propone un principio de justicia que tendría que anteceder al principio de la igual libertad que propone Rawls en su teoría de justicia, que a Villoro le parece adecuado, pero posterior. Para él, primero debe garantizarse que las personas puedan fungir como sujetos morales. Para garantizar esto, incluso podrían restringirse ciertas libertades siempre que se haga solo por el lapso necesario para remediar la carencia de los excluidos; que esta reducción tenga de verdad como efecto que quienes carecen de las libertades mínimas las alcancen y, sobre todo, que la restricción no afecte, y cito: "las libertades mínimas que requiere todo sujeto moral y son condiciones de la dignidad de la persona" (p. 125).

Este último punto reviste una doble importancia, por un lado habla de la preocupación de Villoro con la libertad de realización de las personas, pero también pone de manifiesto algo: que Villoro sostiene que ciertas libertades mínimas son condición de la dignidad de la persona y esto es lo que nos permite vincularlo con la idea de Nussbaum de que una vida bajo cierto umbral de capacidades básicas es indigna de la humanidad.

\section{LAS CAPACIDADES DE FUNCIONAR}

Una vez que hemos expuesto algunos de los elementos centrales de la teoría de la exclusión y la injusticia de Luis Villoro, mostraremos de qué manera se relaciona con la teoría de las capacidades de Amartya Sen, que luego continuó Martha Nussbaum.

Igual que Luis Villoro, Amartya Sen está convencido de que más que una idea abstracta de Justicia, lo que necesitamos es combatir la injusticia: "la justicia no consiste tan solo en tratar de conseguir, o soñar con conseguir, una sociedad o unos esquemas sociales perfectamente justos, sino también en evitar la injusticia manifiesta" (Sen, 2010, p. 53). Sen pone como ejemplo de esto las movilizaciones en favor de la abolición de la esclavitud, que no pretendían un mundo perfectamente justo sino señalar que una sociedad con esclavitud era profundamente injusta: "fue el diagnóstico de la esclavitud como una injusticia intolerable lo que hizo de su abolición una prioridad arrolladora, y esto no exigía la 
búsqueda de un consenso sobre cómo debería ser una sociedad perfectamente justa" (p. 53). Siendo así, lo que necesitamos es un esquema para comparar alternativas posibles, no una idea de la justicia perfecta. En lugar de una teoría que se dedique a establecer los límites de cómo escoger las instituciones y los modos de organización social ideales, requerimos una idea de la justicia que parta de los logros de las personas y se base en las vidas que estas pueden vivir realmente. En este contexto, Sen propone su teoría de las capacidades.

Para Sen, podemos evaluar la calidad de la vida de una persona a partir de un conjunto de funcionamientos interrelacionados. Los funcionamientos son estados o acciones que van desde cosas tan básicas como estar mínimamente bien alimentado, tener salud, evitar una muerte temprana, hasta asuntos más complejos como ser feliz. Así, para Sen, el estado de la vida de una persona está constituido por funcionamientos y por ello estos resultan primordiales para estimar la calidad de la vida de las personas.

Íntimamente ligada con la idea de funcionamientos, está la de "capacidad de funcionar". La capacidad de funcionar ${ }^{6}$ es el conjunto de funcionamientos que la persona puede de hecho realizar. En este sentido refleja la libertad del individuo de llevar uno u otro modo de vida. La calidad de vida de una persona depende de los estados alcanzados. Parece que cuando Villoro dice que "nadie es libre si carece de un tercer género de libertad: la de realización de lo que elige" (Villoro, 2000, p. 121), está pensando en algo muy similar a cierto tipo de capacidades. Recordemos que para gozar de esta "libertad de realización" las personas deben tener cubiertas ciertas necesidades de sobrevivencia y convivencia: quien no tiene alimento y abrigo no es libre de realizar aquello que valora. Luego veremos que en la lista de Nussbaum aparecen capacidades muy similares a los valores objetivos que propone Villoro y que señalamos arriba.

Sen hace hincapié en la importancia de defender la capacidad de las personas frente a los distintos funcionamientos, y es que la capacidad de funcionar es reflejo de la libertad para alcanzar los funcionamientos que valoramos. Así, está preocupado por la libertad y no por los medios para alcanzarla. Sen sostiene que el hecho de tener el poder de elegir nuestro futuro, afecta directamente la calidad de nuestras vidas. Y es que no es lo mismo "hacer x" que "elegir hacer x y hacerlo". Sin duda, es relevante para el estado en el que se halla nuestra vida la manera en la que lo hemos alcanzado. Para mostrar lo anterior, Sen ofrece un ejemplo muy famoso: imaginémonos a una persona que no prueba bocado por semanas y esto lleva a su cuerpo a un estado de completa inanición. ¿No resulta relevante saber si esta persona pasa hambre porque es un asceta que ha elegido ayunar o si pasa hambre porque es un niño en medio de una hambruna que no tiene otra opción? No es lo mismo pasar hambre (hacer $\mathrm{x}$ ) que elegir pasar hambre $\mathrm{y}$ hacerlo (elegir hacer $\mathrm{x} y$ hacerlo).

\footnotetext{
${ }^{6}$ Además del conjunto de funcionamientos, "capacidad de funcionar" también se refiere a una capacidad particular de una manera específica de funcionar: la capacidad de estar bien alimentado, por ejemplo.
} 
Recordemos que el enfoque de Sen pretende ser comparativo y, siendo así, surge el siguiente problema: si los funcionamientos que unos valoran no son valiosos para los demás ¿cómo escogemos qué comparar? Sen reconoce que su perspectiva es pluralista y está abierta: hay que seleccionar y ponderar funcionamientos valiosos, para ello necesitamos razonamiento público que alcance ordenamientos parciales de preferencias y acuerdos limitados, dice Sen (2010):

Puede ocurrir, por supuesto, que el acuerdo basado en los valores relativos esté lejos de ser completo, y entonces tendremos buena razón para emplear jerarquías de valores relativos sobre los cuales podamos alcanzar algún acuerdo. Esto no tiene que alterar de manera fatal la evaluación de la injusticia o la elaboración de las políticas públicas [...] para mostrar que la esclavitud reduce de manera severa la libertad de los esclavos o que [...] la desnutrición aguda de los niños, que causa agonía inmediata y atraso de las capacidades cognitivas, incluida la habilidad de razonar, es una afrenta a la justicia, no necesitamos un único conjunto de valores relativos sobre las diferentes dimensiones implicadas en tales juicios (p. 273).

En fin, desde el enfoque de Sen no hay escapatoria al problema de la evaluación y la selección de funcionamientos para comparar vidas. Pero, por ejemplo, cuando nos ocupamos de la pobreza, parece que adelantamos mucho escogiendo un número limitado de funcionamientos y sus capacidades correspondientes: "la capacidad de estar bien alimentado y disponer de alojamiento, la capacidad de eludir posibles enfermedades y una mortalidad prematura" (Sen, 1995, p. 59). De hecho, en una conferencia dictada en 1979 en la universidad de Stanford, Sen llamó a estas capacidades "básicas" "para diferenciar la capacidad de satisfacer ciertos funcionamientos elementales y básicamente importantes hasta ciertos niveles" (p. 59). Es decir, hay capacidades imprescindibles para que las más complejas sean posibles, y en esto no queda mucho que consensuar: no es difícil aceptar que antes de planear nuestras vidas e intentar llevar a cabo nuestros objetivos, tenemos que estar vivos, tener cierto nivel mínimo de salud y de posibilidad de recibir educación y prosperar. Ahí donde faltan estas capacidades, parece que estamos de acuerdo, nos encontramos ante la injusticia y hay que remediarla.

\section{CAPACIDADES Y DIGNIDAD HUMANA}

Martha Nussbaum dice (2000, pp. 70-86) que si bien su versión de la teoría de las capacidades se parece a la de Sen, es distinta en aspectos importantes, por ejemplo: Sen usa su enfoque, como vimos, para hacer comparaciones respecto de la calidad de vida, mientras que ella la usa, dice, de manera más exigente: como fundamento de principios políticos básicos que sean sustento de garantías constitucionales. La idea principal de su acercamiento es doble: por un lado señala que hay ciertos funcionamientos que son centrales para la vida humana, en el sentido fuerte de que su ausencia o presencia se entiende 58 | AlPha No50 (Julio 2020) PÁGS. 51-65. ISSN 07 16-4254 
como una marca de la presencia o la ausencia de vida humana. Por el otro lado, su acercamiento sostiene que hay algo en llevar a cabo estas funciones de manera humana y no meramente animal: juzgamos con suficiente frecuencia, sostiene, que hay vidas tan empobrecidas que ya no están a la altura de la dignidad de un ser humano, son vidas que se siguen viviendo como hace un mamífero no humano, pero en las que no es posible ejercitar de lleno los potenciales humanos. Una vida que es realmente humana, dice Nussbaum, es aquella que es definida mediante los poderes humanos de la razón práctica y la sociabilidad. Razón práctica que solo se puede ejercitar si se goza de las libertades mínimas que ya exigía Villoro y que Nussbaum también reúne en su lista de capacidades. Y sociabilidad que igual que en Villoro, es espacio de realizaciones. Nussbaum la enlista como capacidad fundamental.

Podemos juzgar que la falta de una capacidad para realizar una función central es tan extrema que la persona que la padece ya no es un ser humano. Esto sucede en algunos casos de enfermedades mentales, por ejemplo. Pero Nussbaum no está interesada en esa frontera, sino en otro umbral: el nivel en donde la vida de una persona se vuelve indigna de un ser humano. Así, lo que el acercamiento de las capacidades de Nussbaum busca, es una sociedad en la que las personas sean tratadas como dignas de respeto y se hallen en una posición en la que puedan vivir de manera realmente humana. Cuando lo anterior no sucede y las personas viven sin capacidades, nosotros diremos que padecen humillación de la dignidad. De hecho, la posibilidad de gozar de una de las capacidades que citamos más adelante y que Nussbaum llama de "afiliación" requiere que las personas vivan en una sociedad donde se den las bases para expulsar la humillación, es decir, una sociedad donde las personas sean tratadas como seres dotados de dignidad e igual valor que los demás.

Nussbaum está convencida de que podemos llegar a una lista de funcionamientos centrales que pueden alcanzar un amplio consenso transcultural. La lista provee, como decíamos, los puntos básicos de principios políticos que han de incorporarse como garantías constitucionales. Por ello, distingue aquellas capacidades que pueden considerarse de importancia central en cualquier vida humana, sin importar las metas particulares de las personas. Las capacidades centrales no son instrumentales, sino que tienen valor en sí mismas, por hacer que la vida que las contiene sea enteramente humana. Sin embargo, también tienen un papel fundamental en todo lo demás que las personas planean y hacen.

Nussbaum propone diez capacidades que son "requisitos básicos para una vida digna" (2007, p. 87), los criterios fundamentales para escogerlos, dice, "deberían ser, en mi opinión, la idea de la dignidad humana, y la idea estrechamente relacionada de las bases sociales del autorrespeto y la no humillación. La igualdad de capacidades es un objetivo social esencial allí donde su ausencia traería consigo un déficit en la dignidad y el autorrespeto" (p. 290). Nombraremos como muestra tres de estas diez capacidades, que además se parecen mucho a los valores objetivos que, como decíamos, defiende Villoro: 
- Vida. Poder vivir hasta el término de una vida humana de una duración normal; no morir de forma prematura $\mathrm{o}$ antes de que la propia vida se vea tan reducida que no merezca la pena vivirla.

- Salud física. Poder mantener una buena salud, incluida la salud reproductiva; recibir una alimentación adecuada; disponer de un lugar adecuado para vivir.

- Afiliación.

1) Poder vivir con y para los otros, reconocer y mostrar preocupación por otros seres humanos, participar en diversas formas de interacción social; ser capaz de imaginar la situación de otro.

2) Que se den las bases sociales del autorrespeto y la no humillación; ser tratado como un ser dotado de dignidad e igual valor que los demás. Eso implica introducir disposiciones contrarias a la discriminación por razón de raza, sexo, orientación sexual, etnia, casta, religión y origen nacional" (Nussbaum, 2007, p. 88).

Para Nussbaum, si imaginamos cómo sería una vida sin las capacidades básicas, tendremos elementos para afirmar que es una vida que no va de acuerdo con la dignidad humana. Por otro lado, reconoce que su teoría es incompleta porque solo se centra en el derecho de las personas a tener una vida conforme a la dignidad humana: "el enfoque ha insistido únicamente en la idea de la adecuación o la suficiencia, y ha dejado la cuestión de qué hacer con las desigualdades por encima de este mínimo como una cuestión ulterior aún por responder" (p. 289). Esto pone de manifiesto la urgencia por resolver la indignidad frente a otras desigualdades o exclusiones.

También es importante señalar que si bien Nussbaum propone una lista de capacidades, no la considera cerrada, es la lista que ella propondría para construir un consenso razonable entre distintas culturas, pero que bien puede ser modificada si se ofrecen buenas razones y alternativas para ello, Nussbaum como Sen y como Villoro, es defensora de la deliberación pública y los puntos de vista sensatos de personas razonables.

\section{EXCLUSIÓN Y HUMILLACIÓN}

Vincularemos ahora exclusión con humillación. Evelin Lindner dice (2006) que la palabra "humillación" tiene, en buena medida, un sentido espacial: implica degradar, hacer menos. Según ella, en cualquier lengua ${ }^{7}$ encontramos que la orientación espacial hacia abajo se relaciona con palabras que significan humillación. ¿Por qué organizamos y

\footnotetext{
${ }^{7} \mathrm{Ni}$ siquiera intentamos verificarlo, aunque siempre llaman la atención estas afirmaciones que pretenden sustentar algo de "todas" las lenguas. Por mera curiosidad, y no como prueba de nada, acudimos al gran diccionario náhuatl para buscar la palabra humillación y sí, en efecto, humillar, que se dice "tlalchitlaza", también quiere decir: abatir al otro hasta el suelo.
}

60 | Alpha No50 (Julio 2020) PÁGS. 51-65. ISSN 07 16-4254 
jerarquizamos el mundo en una escala de arriba a abajo? Quizá es la fuerza de gravedad, dice Lindner, que mantiene nuestros pies en la tierra. Observadores objetivos de otras partes del universo podrían encontrar nuestra fijación con el arriba y el abajo un poco tonta. Sin embargo, todos los que moramos en la tierra compartimos el ímpetu de la gravedad, así que tenemos como marco común la escala vertical, el tironeo hacia abajo. De hecho, esta referencia está tan metida en nuestra conciencia que la usamos como una metáfora inconsciente para lo bueno y lo malo, para valorar el mundo de los seres vivos y también el de las cosas inanimadas. Así, dice Lindner, por dar un ejemplo, el oro está arriba en la escala, un poco más abajo la plata, y mucho más abajo el polvo. En el caso de los seres vivos, la divinidad (si existiera) está en la cima, muy por debajo estamos los humanos y más abajo los otros mamíferos, luego los crustáceos, las bacterias, etcétera.

El concepto del honor está íntimamente ligado con la escala vertical y además suele ser un fenómeno de grupo, a diferencia de la dignidad, que es del individuo. Tan es de grupo que las personas se pueden ver involucradas en affaires d'honneur, sin deberla ni temerla: por ejemplo, citemos un caso reciente. En agosto de 2015 Amnistía Internacional hizo público que un consejo rural en Uttar Pradesh, India, condenó a dos hermanas, una mujer de 23 años, y su hermana de 15, a ser violadas y expuestas en público, desnudas. Su crimen: el hermano se fugó con una mujer casada que pertenecía a la casta gobernante, Jak.

Dice Linder ${ }^{8}$ que hoy muchas mujeres piensan que ser golpeadas por su marido es normal y cita el capítulo de la violencia de género del reporte acerca del estado de la población mundial 2005, en donde se informa que el 94 por ciento de las mujeres de Egipto respondieron que les parecía aceptable ser golpeadas por sus maridos, el 91 por ciento de las mujeres de Zambia respondió igual. Las mujeres, dice el reporte, piensan que las golpizas se justifican por razones como rehusarse a tener sexo o por no tener la comida a tiempo.

¿Qué consecuencias tienen estas ideas? se pregunta Lindner. La respuesta nos la da, afirma, la teoría de la evaluación cognitiva de las emociones: en una cultura que legitima golpear a la esposa, se considera que una mujer desobediente está faltándole el respeto no solo a su esposo, sino a todo el orden social. Así, es posible que la esposa acepte el dolor de la golpiza por considerarlo justificado y benéfico para la estabilidad social. Seguramente a lo largo de los siglos, muchos seres padecieron en silencio humillaciones similares por motivos parecidos. En las sociedades de honor, los estratos son estáticos y las personas de los estratos bajos aceptan que su posición es la que es, de la misma forma que llegan las olas a la playa, o que hay personas más altas que otras.

Lindner, pero también Charles Taylor y Peter Berger (entre otros muchos) hablan de cómo las revoluciones del siglo XVIII trajeron consigo el inicio de la obsolescencia de

\footnotetext{
${ }^{8}$ Sen y Nussbaum también tocan el tema de las preferencias adaptativas que es acomodar las preferencias individuales al contexto, por más que este sea indigno.
} 
las sociedades de honor y dieron paso a la edad de la igual dignidad. Dice Evelin Linder que los ideales de los derechos humanos trajeron consigo un conjunto distinto de realidades que erosionaron la vieja edad del honor para dar paso a la edad de la dignidad. En la edad del honor, la emoción negativa era el miedo, en la edad de la dignidad es la humillación. El nuevo sentimiento moral condena el hecho de tratar a los demás de forma que degrade su valor. Hoy podemos afirmar, dice, que subyugar, instrumentalizar o hacer menos a otro ser humano es ilegítimo y se llama humillación. Humillación, en este sentido, significa la violación ilícita de la igual dignidad.

Pero no siempre fue ilegítimo subyugar o instrumentalizar a otros. En las sociedades organizadas alrededor del honor, la humillación es aceptada ${ }^{9}$ y es de cuatro tipos generales: "la humillación por conquista", que se usa para subyugar a los vecinos y convertirlos en esclavos. Podríamos decir que es la humillación fundadora, la primera que jerarquiza a los humanos entre amos y siervos, la primera que rebaja al otro y niega su igual dignidad. Una vez establecida esta escala vertical el amo usa la "humillación de refuerzo" para mantener su lugar. Esta humillación va desde ciertas reglas abusivas hasta medidas brutales como golpizas, los golpes de los maridos a sus mujeres en las sociedades de honor son "humillación de refuerzo". Una tercera forma de humillación es la de degradación, que se usa para hacer menos aún a alguien que ya está abajo en la jerarquía, por ejemplo, cuando un esclavo de la casa era enviado a trabajar en los campos de caña. La cuarta forma de humillación es por exclusión e implica excluir a las víctimas de la sociedad, ya sea mediante el exilio o la muerte.

Vistas por medio de los derechos humanos, todos estos tipos de humillación se convierten en humillación por exclusión, ya no es exclusión del reino o de la ciudad, es exclusión de la humanidad: cuando una persona tiene que vivir sin poder gozar de las capacidades básicas, como haría un animal, es excluido de la vida humana. Y será esta exclusión de la humanidad, o carencia de capacidades básicas o falta de libertad de realización lo que llamaremos, tomando el nombre que le da Lindner, "humillación de la dignidad".

\section{HUMILLACIÓN, LA EXCLUSIÓN DE LA HUMANIDAD}

Este texto tenía tres propósitos: el primero era mostrar que la humillación de la dignidad es inaceptable, para ello acudimos a los argumentos de Villoro, Sen y Nussbaum, a la vez que vinculamos la exclusión con la humillación. Pero ese es el segundo paso.

Como vimos, Villoro habla de una idea donde se hace un consenso en que se aceptan ciertas diferencias y otras se excluyen. Las diferencias por las que se excluye

\footnotetext{
${ }^{9}$ No podemos hablar en pasado de las sociedades basadas en el honor, siguen presentes, coexisten con las basadas en la dignidad.

62 | AlPha No50 (Julio 2020) PÁGS. 51-65. ISSN 07 16-4254
} 
pueden ser muchas: desde ideas, hasta el color de la piel, la clase social, el lugar de nacimiento. Todas estas exclusiones ilegítimas lastiman y son, dice Villoro, el mal radical: se excluía a las mujeres del voto y de la vida pública en general, a los negros y a los indios de la ciudadanía, a los que no fueran cristianos de ciertos reinos. Como vimos, según la exclusión será la experiencia de la misma y la reivindicación que se planteará para remediarla.

Hay exclusiones cuya atención es más urgente que otras, y no porque las segundas no causen daño, sino porque las primeras suelen ser, si no de vida o muerte, sí determinantes en la calidad de la vida de una persona. Villoro tiene bien claro, y por eso sugiere modificar la teoría de la justicia de Rawls, que primero que todo debe garantizarse que las personas puedan fungir como sujetos morales a partir de las libertades mínimas que requiere todo sujeto moral para tener dignidad: "todas las personas tienen igual derecho a los valores básicos de sobrevivencia y convivencia, como condiciones para fungir como sujetos morales. Deben eliminarse, en consecuencia, en cada situación histórica, las exclusiones que lo impidan" (Villoro, 2000, p. 126). En este sentido concuerda con Amartya Sen, que propone las capacidades básicas que ya vimos y con Martha Nussbaum, que entre sus diez capacidades incluye unas muy similares a los valores objetivos de Villoro, asunto que también mencionamos.

El proceso para mostrar el daño, como diría Villoro, o para tomar en cuenta un funcionamiento determinado, o su falta, en la evaluación de los mundos posibles, como propone Sen, implicará una disputa argumental. Esto no quiere decir que todo el tiempo tengamos que partir de cero a la hora de discutir lo que es y no, aceptable. Sucede que las buenas razones son estables, no tenemos que sustentarlas cada vez que comenzamos a discutir. Por ejemplo, una vez que le mostramos a un apostador que es falso que en la ruleta aumentan las posibilidades de que salga un número negro después de que han salido cinco rojos al hilo, y lo entiende, no tendremos que explicárselo cada vez que quiera apostar a la ruleta. Esto, por supuesto, no quiere decir que ya no podamos discutir acerca de un asunto bien establecido, quiere decir que ya lo hemos discutido ampliamente y que resulta complicado pensar en razones que nos hagan cambiar de parecer. Por ejemplo, ¿qué razones podríamos dar hoy para defender como Aristóteles o Ginés de Sepúlveda que hay personas que son esclavos por naturaleza?

Lo segundo que queríamos mostrar era la relación entre exclusión y humillación de la dignidad. Como dijimos desde el principio, nos parece que el vínculo entre estos conceptos se halla en el acercamiento de Martha Nussbaum, debido a que señala claramente que vivir sin gozar de ciertas capacidades es hacerlo por debajo de la dignidad humana. Lo anterior deja al descubierto el vínculo de la exclusión como la entiende Villoro, con la indignidad: dijimos que la exclusión es negar la equidad y pertenencia a la sociedad de consenso a los distintos, donde "equidad" es trato igual ante la aplicación de una norma. Así, por ejemplo, aquel que no goza de las libertades básicas estipuladas en la constitución 
de su sociedad, es tratado con inequidad si hay otros que sí pueden hacerlo y, además, está excluido. Podemos volcar esta carencia en el ejercicio de las libertades al modelo de las capacidades y ver cómo resulta en la ausencia de varias de ellas y así en una vida bajo el umbral de la dignidad humana. Para terminar de hilar cabos, si la humillación de la dignidad es la violación ilícita de la dignidad humana, entonces la falta de capacidades básicas y la exclusión de cosas tan fundamentales como las libertades de realización son humillación de la dignidad. Y ¿por qué es importante usar este otro concepto? Explicar lo anterior es nuestra tercera meta. El concepto de "humillación de la dignidad"tiene una ventaja en su uso teórico y también práctico sobre las ideas de "exclusión" y "desigualdad". Expliquemos el punto: la exclusión no se contrapone definitivamente con la inclusión, como bien explican Mascareño y Carvajal (2015) hay autoinclusión y autoexclusión, subinclusión, inclusión compensatoria, inclusión en la exclusión, y por ello no puede señalar un mal radical, no es suficientemente tajante.

A diferencia de la exclusión, la humillación de la dignidad es siempre inaceptable y debemos combatirla por injusta. Esto no quiere decir que dejemos de usar el concepto de "exclusión", que es perfectamente explicativo y útil en ciertos campos y aquí mismo. Lo que sugerimos es utilizar "humillación de la dignidad" para señalar lo inaceptable y urgente y combatirlo, porque frente a la humillación no hay mucho más que discutir. De este modo, además, nos parece el concepto idóneo para comenzar a transitar la vía negativa hacia la justicia: quizá no sabemos cuál es la idea de justicia que debe ordenar las instituciones de la sociedad, pero sí sabemos que debemos alejarnos del daño, del mal radical, de la humillación de la dignidad. Villoro, Nussbaum y Sen, tienen razón cuando enuncian que hay ciertas capacidades humanas que son indispensables para vivir con dignidad: alimento, salud, un albergue, y una vida en sociedad. Sin estas capacidades los seres humanos son esclavos de sus necesidades y solo pueden llevar una vida llena de pesares y humillación: ese dolor que causan los otros cuando nos excluyen de la humanidad.

\section{OBRAS CITADAS}

Berger, Peter (1983). On the Obsolescence of the Concept of Honor. En Hauerwas, Stanley, MacIntyre, Alasdair (eds.). Revisions: Changing Perspectives in Moral Philosophy. Notre Dame: Notre Dame University Press, 1983.

Hamilton, Edith; Cairns, Huntington (2002). The collected dialogues of Plato, Princeton: Princeton University Press.

Lindner, Evelin (2006). Making Enemies; humiliation and International Conflict. Westport: Praeger Security International.

Mascareño, Aldo y Carvajal, Fabiola (2015). Los distintos rostros de la inclusión y la exclusión. Revista CEPAL 116, agosto 2015. 
Nussbaum, Martha (2007). Las fronteras de la justicia; consideraciones sobre la exclusión. Barcelona: Paidós.

- (2000). Women and Human Development; the Capabilities Approach. New York: Cambridge University Press.

Sen, Amartya (2010). La idea de la justicia. Madrid: Taurus.

(1995). Nuevo examen de la desigualdad. Madrid: Alianza Editorial.

Taylor, Charles (1992). "The politics of recognition". En Gutmann, Amy (ed.) Multiculturalism; examining the politics of recognition, Princeton: Princeton University Press.

Villoro, Luis (2012). El poder y el valor; fundamentos de una ética política. México: FCE/ El Colegio Nacional.

— (2007). Los retos de la sociedad por venir. México: FCE. (2000). Sobre el principio de la injusticia: la exclusión. Octavas Conferencias Aranguren. México: Isegoíra 22. 